\title{
ĐÁNH GIÁ KẾT QUẢ PHẪU THUÂTT KẾT HỢP XƯƠNG NEPP VÍT KHÓA ĐIỀU TRI GÃY ĐẦU DƯớI XƯƠ'NG ĐÙI Ở NGƯờI TRƯỞNG THÀNH Có SỰ Hỗ TRỢ CỦA MÀN TĂNG SÁNG
}

\begin{abstract}
TÓM TẮT.
Đắt vấn đề: Nghiên cứu đánh giá kết quả phẫu thuật kết hợp xương nẹp vít khóa điều trị gãy đâu dưới xương đùi ở người trưởng thành có sự hố trợ của màn tăng sáng. Đối tượng và phương pháp nghiên cứu: Nghiên cứu hồi cứu và tiến cứu không đối chứng trên 45 bệnh nhân được quả phẫu thuật kêt hợp xương nep vít khóa điêu trị gãy đâuu dưới xương đưi ở người trưởng thành có sự hỗ trợ của màn tăng sángtừ tháng 1/2019 đến tháng 12/2020. Kết quả: Đa số bệnh nhân ở độ tuổi từ 31 đến 60 tuổi $(42,22 \%)$, tai nạn giao thồng là nguyên nhân dẫn đến chấn thương chiếm tỷ lệ cao nhất $(66,67 \%)$ và cơ chế tai nạn hãy gặp nhất là gián tiếp với tỉ lệ $(77,78 \%)$; tổn thương chủ yếu là nhóm C $(53,33 \%)$ theo phân loại tiêu chuẩn AO. Kết quả chung theo thang điểm của Sander R. tốt và rất tốt chiếm tỷ lệ cao $62,22 \%$, trung bình là 28,89\%, kém là 8,89\%. Kết luận: Gãy kín đâuu dưới xương đùi ở người trưởng thành là tổn thương nặng trong đó gãy nhóm C là gãy phức tạp, ảnh hưởng đến vận động khớp. Phẫu thuật kết hợp xương nẹp vít khóa có hố trỡ màn tăng sáng nhằm nắn chỉnh phục hồi về giải phẫu, cố định ổ gãy vững chắc, tão điều kiện để tập phục hồi chức năng sớm sau phẫu thuật.
\end{abstract}

Tư khóa: Gãy kín đâu dưới xương đùi.

\section{SUMMARY}

ASSESSMENT OUTCOMES OF INTERNAL OSTEOSYNTHESIS LOOKING PLATE SYSTEM TREATMENT OF CLOSED DISTAL FEMUS FRACTURE IN ADULT WITH SUPPORT OF C-ARM

Introduction:. Evaluate the result of internal osteosynthesis looking plate system treatment of closed distal femus fracture in adult. Method: A retrospective and prospective study without control on 45 patients who underwent internal osteosynthesis treatment of closed distal femus fracturefrom 1/2019 to 3/2021. Result: The majority of patients were between the ages of 31 and 60 years old $(42.22 \%)$, traffic accidents were the leading cause of injuries $(66.67 \%)$ and $\mathrm{AO}$ group $\mathrm{C}$ fractures were mainly on $53,33 \%$ cases. The overall outcome according to Sander R. scale, good and excellent accounted for a high rate of $62.22 \%$, fair was $28,89 \%$, and poor was

\footnotetext{
${ }^{1}$ Trường Đại họ Y Hà Nọi,

${ }^{2}$ Bệnh viện Hữu nghi Việt Đức

Chịu trách nhiệm chính: Quế Văn Huy

Email: quehuy95@gmail.com

Ngày nhận bài: 13.9 .2021

Ngày phản biên khoa học: 9.11.2021

Ngày duyệt bài: 16.11.2021
}

\author{
Quế Văn Huy ${ }^{1}$, Nguyễn Xuân Thùy ${ }^{2}$, \\ Vũ Văn Khoa ${ }^{2}$, Vũ Trường Thịnh ${ }^{1}$
}

$8,89 \%$. Conclusion: AO group C closed dital femus fracture in adults is complex intercondylar fracture. The internal osteosynthesis treatment correct anatomical reduction, rigid fixation of fracture in order to improve early rehabilitation after surgery.

Keywords: Close distal femus fracture

\section{I. ĐẶT VẤN ĐỀ}

Gãy đâu dưới xương đùi (ĐDXĐ) là một loại gãy xương lớn và phức tạp, dễ đưa đến nhiêuu biến chứng và di chứng trong các loại gãy xương vùng khớp gối, như di chứng can lệch, hạn chế vận động khớp gối hoặc thoái hóa khớp gối.

Trước năm 1970, phương pháp điêuu trị bảo tồn là chính. Bệnh nhân được xuyên đinh kéo liên tục để nắn chỉnh, sau 2 đến 3 tuân chuyển sang cố định bằng bột [1], [2]. Phương pháp này có nhiều hạn chế như: Các biến chứng do thời gian bất động kéo dài

Điều trị phẫu thuật đã cho nhiêu kết quả khả quan như liền xương, phục hồi chức năng. Mize R.D. và cộng sự (1982) [3] thông báo điều trị phẫu thuật cho 30 bệnh nhân bị gãy ĐDXĐ kết quả đạt loại tốt là 76.5\%. Tại Việt Nam, Đoàn Lê Dân và cộng sự (1998) [4] thổng báo điêu trị phẫu thuật cho 48 bệnh nhân gãy ĐDXĐ đạt kết quả tốt là 47,9\%.

Trong thời gian học tập tại Bệnh viện Hữu nghị Việt Đức và qua tìm hiểu thực tế chúng tôi thấy chưa có nhiều nghiên cứu, báo cáo tổng kết đây đủ về phẫu thuật kết hợp xương nẹp vít trong gãy kín đâuu dưới xương đùi ở người trưởng thành có hỗ trợ màn tăng sáng. Chính vì vậy chúng tôi tiến hành nghiên cứu nhằm đánh giá hiệu quả của phương pháp này tại Bệnh viện Hữu nghị Việt Đức.

II. ĐỐI TƯỢNG VÀ PHƯƠNG PHÁP NGHIÊN CỨU

2.1. Đối tượng nghiên cứu: 45 bệnh nhân được phẫu thuật kết hợp xương nẹp vít khóa điều trị gãy kín đâuu dưới xương đùi ở người trưởng thành có hỗ trợ màn tăng sáng tại Bệnh viện Hữu nghị Việt Đức từ tháng 1/2019 đến tháng 12/2020.

2.2. Phương pháp nghiên cứu: Mô tả cắt ngang không đối chứng kết hợp hồi cứu (32 bệnh nhân) và tiến cứu (13 bệnh nhân).

2.3. Tiêu chuẩn lựa chọn: 
Tiêu chuẩn lựa chọn: từ 18 tuổi trở lên được chẩn đoán gãy kín đầu dưới xương đùi (trừ loại B3 theo phân loại $A O)$, đủ hồ sơ bệnh án, phim Xquang trước và sau mổ, bệnh nhân đồng thuận tham gia nghiên cứu.

Tiểu chuẩn loại trư:: gãy xương hở, gãy xương bệnh lý, di chứng sau chấn thương, các bệnh nhân không đồng thuận tham gia nghiên cứu.

\subsection{Kĩ thuật:}

- Tư thế $\mathrm{BN}$ : Để $\mathrm{BN}$ nằm ngửa có kê độn dưới khoeo một gối nhỏ. Nếu trường hợp gãy xương phức tạp thì cần phải tính toán sao cho gấp gối được nhiều hơn để thuận lợi cho thì nắn chỉnh và cố định, Garo gốc đùi.

- Đường mổ: đi theo đường mổ phía bên ngoài

Thì 1: Rach da $1 / 3$ dưới đùi theo đường chuẩn đích từ mấu chuyển lớn đến phía sau lồi cầu ngoài xương đùi, đến ngang bình diện khớp gối, sau đó cong nhẹ vào trong xuống tới gần bờ ngoài lồi củ trước xương chày, bóc tách cân cơ bộc lộ đầu dưới xương đùi

Thì 2: Bộc lộ và nắn chỉnh ổ gãy: sau khi bộc lộ ổ gẫy tiến hành bơm rửa lấy hết máu tụ, làm sạch các đầu, diện xương gẫy, nắm chỉnh các mảnh xương vỡ về vị trí giải phẫu, găm kim cố định tạm thời các diện gãy, sau nẳn kiểm tra trên màn hình tăng sáng

Thì 3: Đặt nẹp khóa và kiểm tra bằng màn tăng sáng:

Nắn chỉnh hết các di lệch, chọn và đặt nẹp khóa phù hợp với vị trí và chiều dài của xương. Bờ trước và bờ sau nẹp khóa song song với phần loe rộng của các khối lồi câuu trước và sau. Đầu thấp nhất của nẹp xuống sát chỗ bám của bao khớp phía trên bờ sụn.

Khoan bắt vis khóa trên nẹp theo định hướng ống khoan

Kiểm tra sau bắt vis bằng màn hình tăng sáng

Thì 4: cầm máu và đóng vết mổ

\subsection{Biến số nghiên cứu}

- Thông tin chung: tuổi, giới.

- Nguyên nhân chấn thương

- Triệu chứng lâm sàng

- Đăc điểm tổn thương trên Xquang.

- Thời gian từ khi tổn thương đến khi phẫu thuật

- Phương pháp phẫu thuật: kỹ thuật mổ, đường mổ.

- Kết quả điều trị, biến chứng sau mổ.

\section{KẾT QUẢ NGHIÊN CỨU}

\section{1. Đặc điểm lâm sàng của nhóm đối tượng nghiên cứu}

Bảng 3.1.Đặc điểmcủa nhóm đối tượng nghiên cứu

\begin{tabular}{|c|c|c|c|}
\hline Đặc điếm & Phân loại & Số bệnh nhân ( $n=45)$ & Tỷ lệ (\%) \\
\hline \multirow{3}{*}{ Tuổi } & $18-30$ & 9 & 20 \\
\hline & $31-60$ & 19 & 42,22 \\
\hline & $>60$ & 17 & 38,78 \\
\hline \multirow{3}{*}{$\begin{array}{l}\text { Nguyên nhân } \\
\text { chấn thương }\end{array}$} & Tai nan giao thông & 30 & 66,67 \\
\hline & Tai nạn lao động & 11 & 24,44 \\
\hline & Tai nạn sinh hoạt & 4 & 8,89 \\
\hline \multirow{4}{*}{$\begin{array}{l}\text { Triệu chứng } \\
\text { lâm sàng }\end{array}$} & $\begin{array}{l}\text { Sưng nề và bầm tím vùng dưới đùi và } \\
\text { gối sau chấn thương }\end{array}$ & 45 & $100 \%$ \\
\hline & Đau chói & 45 & $100 \%$ \\
\hline & Cử động bất thường & 15 & $33,33 \%$ \\
\hline & Biến dang chi, bàn chân đố ngoài & 45 & $100 \%$ \\
\hline \multirow{3}{*}{$\begin{array}{l}\text { Phân loại } \\
\text { tổn thương } \\
\text { (AO) }\end{array}$} & A & 16 & 35,56 \\
\hline & B & 5 & 11,11 \\
\hline & $\mathrm{C}$ & 24 & 53.33 \\
\hline \multirow{3}{*}{$\begin{array}{l}\text { Thời điểm } \\
\text { phẫu thuật }\end{array}$} & 1-3 ngày & 18 & 40 \\
\hline & 4-7 ngày & 22 & 48,89 \\
\hline & 8-14 ngày & 5 & 11,11 \\
\hline \multirow{3}{*}{$\begin{array}{l}\text { Thời gian } \\
\text { điêu trị }\end{array}$} & $<7$ ngày & 21 & 46,67 \\
\hline & $7-14$ ngày & 23 & 51,11 \\
\hline & $>14$ ngày & 1 & 2,22 \\
\hline
\end{tabular}

Bảng 3.1 cho thấy đa số BN ở nhóm 31-60 tuổi (chiếm 42,22\%),Nguyên nhân chấn thương chủ yếu là TNGT(66,67\%). $100 \%$ BN có triệu chứng sưng nề và bầm tím vùng dưới đùi và gối sau chấn thương, có $33 \%$ cử động bất thường vì đây cũng không phải yêu cầu bắt buộc tìm thấy khi khám lâm sàng. Tổn thương loại $C$ chiếm tỷ lệ phổ biến nhất với $53,33 \%$, tỷ lệ tổn thương $B$ nhỏ nhất với 11,11\%. Đa số bệnh nhân được phẫu thuật trong tuần đầu tiên tính từ khi chấn thương. Đa số bệnh 
nhân được điều trị trong vòng 2 tuần (14 ngày) kể từ thời điểm vào viện, trong đó thời gian điều trị sau phẫu thuật đa phần dưới 10 ngày.

\subsection{Kết quả điêu trị}

\section{Bảng 3.2. Kết quả gần}

\begin{tabular}{|c|c|c|c|}
\hline Đặc điểm & Phân loại & $\begin{array}{c}\text { Số bệ̂nh } \\
\text { nhân }(n=45)\end{array}$ & $\begin{array}{l}\text { Tỷ lệ } \\
(\%)\end{array}$ \\
\hline Diên biến tai vết mố & Liền vết mố thì đầu & 41 & $91,11 \%$ \\
\hline \multirow{4}{*}{$\begin{array}{l}\text { X-quang } \\
\text { sau mô }\end{array}$} & Trục xương thằng giống như bên lành & 17 & 37,78 \\
\hline & $\begin{array}{l}\text { Nếu mở góc ra ngoài hay ra trước }<5^{\circ} \\
\text { Nếu mơ góc ra sau hay vào trong }<10^{\circ}\end{array}$ & 20 & 44,44 \\
\hline & Nễu vượt quá ngưỡng trên & 8 & 17,78 \\
\hline & Giống tiêu chuấn trung bình và kèm theo di lệch xoay & 0 & 0 \\
\hline
\end{tabular}

\section{Bảng 3.3. Kết quả xa}

\begin{tabular}{|c|c|c|c|}
\hline Đặc điểm & Phân loại & $\begin{array}{c}\text { Số bệnh } \\
\text { nhân(n=37) }\end{array}$ & $\begin{array}{l}\text { Tỷ lệ } \\
(\%)\end{array}$ \\
\hline \multirow{3}{*}{ Tình trạng sẹo mổ } & Mềm mại & 35 & 77,78 \\
\hline & Sẹo lồi & 7 & 15,56 \\
\hline & Sẹo dính và co kéo & 3 & 6,67 \\
\hline \multirow{4}{*}{ Kết quả liền xương } & X-quang: ố gây liền xương vững chắc không di lệch & 25 & 55,56 \\
\hline & $\begin{array}{l}\text { X-quang: ố gây đã liền xương hết di lệch hoặc còn di lệch } \\
\text { ít ở mức độ cho phép }\end{array}$ & 13 & 28,89 \\
\hline & $\begin{array}{l}\text { X-quang: ố gây đó liền xương, có thế khuyết xương, ố } \\
\text { gẫy còn di lệch nhiếu hơn mức độ cho phép }\end{array}$ & 7 & 15,56 \\
\hline & $\begin{array}{c}\text { X-quang: ố gây không liên xương hoặc liền xương giống } \\
\text { như ở mức độ trung bình kèm theo di lệch xoay }\end{array}$ & 0 & 0 \\
\hline \multirow{4}{*}{ Mức độ đau } & Không đau & 20 & 44,44 \\
\hline & Thỉnh thoảng đau hoặc khi thay đối thời tiết & 18 & 40 \\
\hline & Đau khi mệt mỏi & 6 & 13.33 \\
\hline & Đau liên tục & 1 & 2,22 \\
\hline \multirow{4}{*}{ Mức độ gấp gối } & Bình thường & 15 & 33,33 \\
\hline & $110^{0}-125^{0}$ & 17 & 37,78 \\
\hline & $90^{0}-99^{0}$ & 6 & 13,33 \\
\hline & $<90^{\circ}$ & 7 & 15,56 \\
\hline \multirow{4}{*}{$\begin{array}{l}\text { Mức đô hạn chế } \\
\text { duô̂i gối }\end{array}$} & $0^{0}$ & 20 & 44,44 \\
\hline & $5^{0}$ & 18 & 40 \\
\hline & $6^{0}-10^{0}$ & 5 & 11,11 \\
\hline & $>10^{\circ}$ & 2 & 4,44 \\
\hline
\end{tabular}

Bảng 3.4. Kêt quả chung

\begin{tabular}{|c|c|c|c|}
\hline Đặc điếm & Phân loại & Số bệnh nhân (n=45) & Tỷ lệ (\%) \\
\hline \multirow{2}{*}{ Theo thang } & Rất tốt & 10 & 22,22 \\
\cline { 2 - 4 } điểm của & Tốt & 18 & 40 \\
\cline { 2 - 4 } Sander R. & Trung bình & 13 & 28,89 \\
\cline { 2 - 4 } & Xẫu & 4 & 8,89 \\
\hline
\end{tabular}

Kết quả gần sau mổ là tốt với $91,11 \%$ bênh nhân liền vết mổ kỳ đầu. XQ sau mổ hết di lệchvà di lệch ít trong mức cho phép là $82,22 \%$. Kết quả xa sau mổ với tình trạng seo mồ mềm mai chiếm tỷ lê cao với $77,78 \%$, tỷ lể liền xương hểt di lệch $55,56 \%$, mức độ hết đau và thỉnh thoảng đau chiếm tî lệ cao 84,44 . Kết quả chung bệnh nhân đạt tốt và rất tốt chiếm 62,22\%.

\section{BÀN LUÂN}

Trong nhóm nghiên cứu của chúng tôi, tuổi trung bình là $51,04 \pm 19,06$, đa số là tuổi lao động với số bênh nhân dưới 60 tuổi chiếm $62,22 \%$. Qua số liệu này cho thây, số BN ở lứa tuổi trẻ và trung niên, đang ở độ tuổi lao động chiếm phần lớn, điều này cũng nói lên nguyên nhân gây tai nạn chủ yếu do năng lượng cao, đang tham gia gia thông nhiều. Kết quả này gần tương đương với kết quả nghiên cứu của Lê Quốc Huy (2003) [5] là 78,4\%, Nguyễn Huy Thành (2009) [6] là 85,2\%.

Theo kết quả nghiên cứu của chúng tôi thì nguyên nhân gãy kín đầu dưới xương đùi chủ 
yếu do là do TNGT 30/45 BN (66,67\%), tiếp đến các nguyên nhân khác như TNLĐ có $11 / 45$ BN $(24,44 \%)$; TNSH có $4 / 45$ BN $(8,89 \%)$.

Tỉ lệ TNGT của chúng tôi tương đương với Nguyễn Huy Thành (2009) [6] là 80,3\%. Lớn hơn so với các tác giả nước ngoài như Mize (1989) [7] thì tỷ lệ gặp do TNGT là $58 \%$. Khan AM (2017) [8] thì tî lệ gặp do TNGT là 26,6\%. Có lẽ đây là đặc thù TNGT quá phổ biến ở Việt Nam hiện nay.

Như vậy ở Việt Nam nguyên nhân chính vẫn là do TNGT, đó cũng là nguyên nhân chung của các chấn thương khác nhau như CTSN, gãy xương cẳng chân, xương đùi. Điều này cho thấy tình hình TNGT nói chúng và việc tuân thủ các biện pháp an toàn giao thông nói riêng vẫn đang là vấn đề bức xúc cần được giải quyết để giảm thiểu số tai nạn. Ở độ tuổi trên 60, nguyên nhân dẫn đến gãy đầu dưới xương đùi lại là tai nạn sinh hoạt trong đó đa phần là bệnh nhân nữ. Trong thực tế, lứa tuổi trên 60 thì quá trình loãng xương ở phụ nữ diễn ra nhanh và mạnh hơn nam giới, nguyên nhân chủ yếu ở lứa tuổi này là do TNSH ngã.

4.2. Đặc điểm lâm sàng. Trong nghiên cứu này ta thẩy hầu hết các $B N$ gẫy kín đầu dưới xương đùi đều có các đặc điểm lâm sàng của gãy xương nói chung, đau chói $100 \%$, sưng nề và bầm tím vùng dưới đùi và gối sau chấn thương 100\%, biến dạng chi, bàn chân đổ ngoài $100 \%$, dấu hiệu cử động bất thường khám được là $33,33 \%$, đây cũng phản ánh vấn đề không nên cố gắng tìm dấu hiệu cử động bất thường bằng các động tác khám tránh tình trạng làm đau và nặng thêm bệnh.

Bệnh nhân được bất động tạm thời trước phẫu thuật là $100 \%$, trong đó bất động bằng nẹp chuyển dụng chiếm tỉ lệ cao nhất $66,67 \%$, kéo liên tục chỉ áp dụng cho trường hợp phần mềm phẫu thuật trước mổ kém. Nhờ bất động trước mổ tốt giúp tránh các biến chứng tại chổ và toàn thân cho bệnh nhân, giúp cuộc mổ diễn ra tốt đẹp hơn.

4.3. Đặc điểm Xquang. Trong nghiên cứu này chúng tôi sử dụng cách phânloại theo $\mathrm{AO}$ [6], tổn thương thuộc nhóm $C$ chiếm tỉ lệ cao nhất $(55,33 \%)$, thấp nhất là nhóm $B(11,11 \%)$, trong nhóm $C$ thì loại $C 2$ chiếm tỉ lệ cao nhất. Điều này có thể do gãy đầu dưới xương đùi là một phẩu thuật khó nên các bệnh nhân nặng được chuyển về Bệnh viện Việt Đức đặc biệt nhửng trường hợp gãy phức tạp. Tỷ lệ ở mức C2 tương đương với một số tác giả khác.

Việc chẩn đoán mức độ gãy dựa trên Xquang trước mổ rất quan trọng, cần đánh giá chính xác tổn thương để có kế hoạch chuẩn bị lựa chọn phương pháp và kỹ thuật phù hợp. Thực tế khi mổ tổn thương thường nặng hơn hình ảnh trên Xquang rất nhiều, những mảnh và đường gãy nhỏ nhiều khi rất phức tạp trên phim Xquang thường không thấy hết, vì vậy cần chuẩn bị sẵn sàng đây đủ phương tiện, dụng cụ cho các loại gãy.

4.4. Kết quả phâuu thuật. Đa phần các bệnh nhân đều liền da ngay thì đầu $(91,11 \%)$, không có trường hợp nào nhiễm khuẩn sâu hay rò mủ kéo dài.Theo Dương Duy Thanh (2019) [9] tỉ lệ nhiếm trùng nông vết mổ là $5,56 \%$ và không có bệnh nhân nào nhiễm trùng sau vết mổ. Theo kinh nghiệm của chúng tôi, để hạn chế nhiễm trùng vêt mổ ngoài vấn đề vố trùng trong mổ thì cần phải đánh giá chính xác thương tích phần mềm; nếu thương tích phần mềm nặng, đùi sưng nề nhiều, rối loạn dinh dưỡng thì cần đặt nẹp bột tạm thời, chườm lạnh, giảm phù nề, kéo liển tụ̣c và chỉ phấu thuật khi phần mềm ổn định, không vội vàng.

Kết quả Xquang sau mổ:37/45 BN của chúng tôi được nắn chỉnh hết di lệch và di lệch ít trong phạm vi cho phép, chiếm $82,22 \%$, còn 8 BN $(17,78 \%)$ di lệch lớn hơn mức cho phép nhưng không có bệnh nhân nào có di lệch xoay. Những trường hợp này là gãy đầu dưới xương đùi loại C2，C3，gãy rất phức tạp, có nhiêu mảnh rời, phải đặt nẹp bột, giữ 6 tuần sau mổ. Theo kinh nghiệm của chúng tôi, với những gãy phức tạp loại $\mathrm{C} 2, \mathrm{C} 3$, để nắn chỉnh được ổ gãy như mong muốn, trước hết cần lựa chọn đường mổ hợp lý. Đường mổ này rộng rãi cho phép bộc lộ rõ ràng ổ gãy đầu dưới xương đùi để đặt lại ổ gãy như mong muốn, bên cạnh đó có công cụ màn tăng sáng hỗ trợ trong mổ. Với kết quả Xquang tốt, BN sẽ tập phục hồi chức năng sớm sau mổ.

4.5. Kết quả sau mổ. $45 \mathrm{BN}$ nghiên cứu có kết quả liền xương tốt hoặc trung bình, không có trường hợp nào chậm liền xương hay khớp giả, chiếm 100\%. Trong đó, 25 BN (55,56\%) hình thành can xương gọn, đường gãy không còn rõ, thẳng trục ở tư thế thẳng, chúng tôi đánh giá là liền xương tốt, hết di lệch. Có 7 bệnh nhân liền xương nhưng vẫn còn ổ khuyết xương và ổ gãy còn di lệch nhiều hơn mức cho phép chiếm $15,56 \%$, đa phần là những trường hợp gãy phức tạp, di lệch nhiều thuộc nhóm C theo phân loại AO.

Kết quả nghiên cứu chúng tôi đánh giá theo thang điểm Sander $R$. cho thấy: tỷ lệ rất tốt là $22,22 \%$, tốt là $40 \%$, trung bình $28,89 \%$, xấu $8,89 \%$. Kết quả này cũng tương xứng với các két quả nghiên cứu khác như: Nguyễn Hồng Dương 
năm 2013 (học viện quân y) thì kết quả tốt và rất tốt là $70 \%$, George (2010) trong 38 BN đạt tốt và rất tốt là $84 \%$

\section{KẾT LUÂ̂N}

Gãy kín đầu dưới xương đùi là một gãy xương lớn và phức tạp, độ tuổi gặp thường là độ tuổi lao động nên nhu cầu phục hồi sớm về mắt giải phẫu và độ vững chắc sau phẫu thuật để bệnh nhân tập phục hồi chức năng sau mổ là rất quan trọng, kết quả cho thấy phương pháp kết hợp xương bằng nẹp vis khóa có hố trợ màn hình tăng sáng mang lại hiệu quả hồi phục cao và sớm cho bệnh nhân.

\section{TÀI LIÊUU THAM KHẢO}

1. Đoà̀n Lê Dân, Đoàn Viêt Quân (1992), Xơ cứng duối gối ở người lớn, Nhà xuất ban y học, tr. $113-115$

2. Mooney V., Nickel V. L., Harvey J.P and Snelson R. (1970), Cast brace treatment for fracture of the distal part of the femur. J.Bone \& joint surg. 52A. p.1560.

3. Mize R.D., Bucholz R.W and Grogan D.P. (1982), Surgical treatment of displaced comminuted fractures of the distal end of the femur. J.Bone \& joint surg. 64A, p.871.

4. Đoàn Lê Dân, Đoàn Viêtt Quân (1998), Xử trí gãy trên lồi cầu và liên lối cầu xương đưi do tai nan giao thông tai Bênh viên Viêt - Đức Hà Nội, Tạp chí Ngoai khoa số 6/1998, tr.9 - 17

5. Lề Quốc Huy (2003). Đánh giá kết quả phẫu thuật kết hợp xương điều tri gâyy kín phạm khớp đâuu dưới xướng đùi người lớn tại bệnh viện Việt Đức. Đại học Y Hà Nội, Luận văn tốt nighiệp bác sỹ CKII, trr $12-15$.

6. Nguyê̂n Huy Thành (2009). Đánh giá kết quả điều trị phâuu thuật gẫy kín trên lồi câu và liên lồi cầu xương đùi ngưới lớn tại bệnh viện Hữu nghị Việt Đức. Trường Đại học Y Hà Nội, Luận văn thạc sĩ y học.

7. Mize R.D. (1989). Surgical management of complex fractures of the distal femur. Clin. Orthop 243, pp.115-128.

8. Akib Majed Khan,* Quen Oat Tang, and Dominic Spicer (2017). The Epidemiology of Adult Distal Femoral Shaft Fractures in a Central London Major Trauma Centre Over Five Years. Open Orthop J.

9. Dương Duy Thanh (2019). Đánh giá kết quả phẫu thuật gãy đầu xa xương đùi ở người trưởng thành tại bênh viện Hữu nghị Việt Đức. Trường Đại học Y Hà Nồi, Luẩn văn thạc sĩ y học.

\section{ĐĂC ĐIỂM LÂM SÀNG, ĐIÊ̂N SINH LÝ HỌC TIM Ở BỆNH NHÂN HộI CHỨNG WOLFF - PARKINSON - WHITE CÓ CO'N RUNG NHĨ}

\section{TÓM TẮT.}

Mục tiêu: Mô tả đặc điểm lâm sàng, điện sinh lý tim ở bệnh nhân hội chứng WPW có cớn rung nhĩ và So sánh đăc điểm lâm sàng, điện sinh lý tim ở bệnh nhân Wolff - Parkinson - White có và không có cớn rung nhĩ. Phương pháp nghiên cứu: Nghiên cứu tiến hành trong 49 đối tượng bao gồm 18 bệnh nhân có cơn rung nhĩ trên lâm sàng hoăc trong thăm dò điện sinh lý và 31 bệnh nhân mắc hội chứng Wolff Parkinson - White. Các bênh nhân được chọn phù hợp với yêu câuu nghiên cứu. Kết quả nghiên cứu: Nghiên cứu cho thây trong nhóm rung nhĩ ở hội chứng WPW: tuổi thường gặp 49,2 \pm 15,6 tuổi, nam chiếm tỳ lệ cao $72,3 \%$, nhóm bệnh tim mạch kèm theo là THA, chức năng nút xoang và dẫn truyền trong tim bình thường, thời gian trơ của đường phụ ngắn, chiều xuôi $247,7 \pm 29,0$, chiều ngược 279,0 $\pm 24,0 P<0,05$. Một đường phụ và vị trí bên phải là thường gặp ở nhóm có rung nhĩ. Kết luận: Giới tính nam, các bệnh kèm theo tăng huyết áp, cường giáp, thời gian trơ của đường

${ }^{1}$ Bệnh viện Đa khoa Khu vực Ngọc Lặc

${ }^{2}$ Bênh viên Bach Mai

Chịu trách nhiệm chính: Lê Sỹ Hiệu

Email: hieutranghscc@gmail.com

Ngày nhận bài: 20.9.2021

Ngày phản biên khoa hoc: 12.11.2021

Ngày duyệt bài: 23.11.2021

\section{Lê Sỹ Hiệu ${ }^{1}$, Trần Song Giang ${ }^{2}$}

dẫn truyền phụ ngắn có thể là các yếu tố có thể ảnh hưởng tới sự xuất hiện của rung nhĩ ở hội chứng WPW.

Từ khóa: Đường phụ, Rung nhĩ, Nhịp nhanh vào lại nhĩ thất, Điện sinh lý tim

Các từ viết tăt: AF: rung nhĩ,THA: tăng huyết áp WPW: hội chứng Wolff - Parkinson - White, tPHNX thời gian phục hồi nút xoang, tPHNXđ thời gian phục hồi nút xoang hiệu chỉnh, TGCKKT thời gian chu k̀̀̀ kích thích, TGTHQ thời gian trơ hiệu quả.

\section{SUMMARY}

\section{THE CLINICAL AND ELECTROPHYSIOLOGICAL CHARACTERISTICS OF PATIENTS WITH WPW SYNDROME WITH ATRIAL FIBRILATION}

Objectives: To describe the clinical and electrophysiological characteristics of patients with WPW syndrome with atrial fibrillation and to compare the clinical and electrophysiological characteristics of patients with Wolff - Parkinson - White with and without fibrillation. atrium. Methods: The study was conducted in 49 subjects, including 18 patients with atrial fibrillation in clinical or electrophysiological studies and 31 patients with Wolff - Parkinson - White syndrome. The patients were selected in accordance with the study requirements. Research results: The study showed that in the group of atrial fibrillation in WPW syndrome: common age was $49.2 \pm 15.6$ years 